\title{
Photorespiratory Metabolism and Nodule Function: Behavior of Lotus japonicus Mutants Deficient in Plastid Glutamine Synthetase
}

\author{
Margarita García-Calderón, ${ }^{1}$ Maurizio Chiurazzi, ${ }^{2}$ M. Rosario Espuny, ${ }^{3}$ and Antonio J. Márquez ${ }^{1}$ \\ ${ }^{1}$ Departamento de Bioquímica Vegetal y Biología Molecular, Universidad de Sevilla, C/ Profesor García González 1, \\ 41012 Sevilla, Spain; ${ }^{2}$ Institute of Genetics and Biophysics A. Buzzati Traverso, Via Pietro Castellino, 111-80131, \\ Napoli, Italy; ${ }^{3}$ Departamento de Microbiología, Facultad de Biología, Universidad de Sevilla, Avda. Reina Mercedes 6 , \\ 41012-Sevilla, Spain
}

Submitted 28 July 2011. Accepted 11 October 2011.

\begin{abstract}
Two photorespiratory mutants of Lotus japonicus deficient in plastid glutamine synthetase $\left(\mathrm{GS}_{2}\right)$ were examined for their capacity to establish symbiotic association with Mesorhizobium loti bacteria. Biosynthetic glutamine synthetase (GS) activity was reduced by around $40 \%$ in crude nodule extracts from mutant plants as compared with the wild type (WT). Western blot analysis further confirmed the lack of $\mathrm{GS}_{2}$ polypeptide in mutant nodules. The decrease in GS activity affected the nodular carbon metabolism under high $\mathrm{CO}_{2}$ (suppressed photorespiration) conditions, although mutant plants were able to form nodules and fix atmospheric nitrogen. However, when WT and mutant plants were transferred to an ordinary air atmosphere (photorespiratory active conditions) the nodulation process and nitrogen fixation were substantially affected, particularly in mutant plants. The number and fresh weight of mutant nodules as well as acetylene reduction activity showed a strong inhibition compared with WT plants. Optical microscopy studies from mutant plant nodules revealed the anticipated senescence phenotype linked to an important reduction in starch and sucrose levels. These results show that, in Lotus japonicus, photorespiration and, particularly, $\mathbf{G S}_{2}$ deficiency result in profound limitations in carbon metabolism that affect the nodulation process and nitrogen fixation.
\end{abstract}

Biological nitrogen fixation is the reduction of atmospheric dinitrogen to ammonia and is an exclusively prokaryotic process that can be, in some cases, carried out by symbiotic bacteria named rhizobia, in association with plants of the family Leguminosae. This symbiosis between rhizobia and plants is a beneficial process to both of them, because carbon and energy are supplied from the plant to the differentiated bacterial cells, termed bacteroids (Ferguson et al. 2010), in the form of dicarboxylic acids to fuel nitrogen fixation. In exchange, fixed nitrogen is transferred to the plant. Recently, it has been postulated that a more complex amino-acid cycle is essential for symbiotic nitrogen fixation by Rhizobium spp. in nodules (Lodwig and Poole 2003; Lodwig et al. 2003; White et al. 2007).

Glutamine synthetase (GS) is the key enzyme involved in the assimilation of ammonia derived either from nitrate reduction or $\mathrm{N}_{2}$ fixation (Forde and Cullimore 1989). Two GS isoen-

Corresponding author: A. J. Márquez; E-mail: cabeza@us.es; Telephone: +34954 557145; Fax: +34954626853. zymes, plastidic $\left(\mathrm{GS}_{2}\right)$ and cytosolic $\left(\mathrm{GS}_{1}\right)$, were identified in higher plants (Cren and Hirel 1999). The GS isoforms have specific, apparently nonredundant, physiological roles in ammonium assimilation (Coruzzi and Last 2000; Lancien et al. 2000; Lea and Ireland 1999). GS2 is predominantly expressed in green tissues, and it has been demonstrated that this isoform has an essential role in the reassimilation of ammonium released by photorespiration (Blackwell et al. 1987; Kozaki and Takeba 1996; Orea et al. 2002; Wallsgrove et al. 1987), although its presence in nonphotosynthetic tissues of temperate legumes has been reported (Woodall and Forde 1996). A second gene encoding for $\mathrm{GS}_{2}$ was recently shown to be exclusively expressed in developing seeds from Medicago truncatula (Seabra et al. 2010). In contrast, $\mathrm{GS}_{1}$ is localized in the vascular tissue and plays an important role in the assimilation of external ammonium, the ammonia derived from $\mathrm{N}_{2}$ fixation and other sources of nitrogen, and in the remobilization of nitrogen during senescence (Edwards et al. 1990; Kamachi et al. 1992; Kichey et al. 2005; Teixeira et al. 2005).

The plant Lotus japonicus is currently used as a model temperate legume, based on its biochemical, physiological, and genetic characteristics (Handberg and Stougaard 1992; Pajuelo and Stougaard 2005). A single Ljgln2 locus encoding for $\mathrm{GS}_{2}$ in this plant was mapped together with other symbiotic loci (Sandal et al. 2006). Two L. japonicus photorespiratory mutants deficient in $\mathrm{GS}_{2}$, denominated Ljgln2-1 and Ljgln2-2 (Betti et al. 2006), were previously isolated and characterized at the molecular level in our laboratory (Orea et al. 2002; Betti et al. 2006) and have been recently used to analyze their transcriptomic response towards drought stress (Diaz et al. 2010). These mutants were specifically affected in $\mathrm{GS}_{2}$, having normal levels of $\mathrm{GS}_{1}$ enzyme activity. It was shown that the lack of $\mathrm{GS}_{2}$ resulted in 70 to $80 \%$ diminution of total GS activity from mutant leaves compared with the wild type (WT). In contrast, no decrease in GS enzyme activity was obtained in roots of the mutant plants. This result would be in accordance with the fact that $\mathrm{GS}_{2}$ constitutes most of the GS activity present in leaves, while in roots, GS enzyme activity must correspond basically to $\mathrm{GS}_{1}$, surely as a consequence of the fact that roots have very few plastids. A singlepoint allelic mutation was identified on each mutant that was responsible for two different amino-acid replacements in the corresponding $\mathrm{GS}_{2}$ proteins. Both mutations affected the stability of $\mathrm{GS}_{2}$ polypeptide, although in a different manner. Small levels of $\mathrm{GS}_{2}$ proteins could be detected in leaves and roots of Ljgln2-1 mutant, but a complete lack of $\mathrm{GS}_{2}$ protein was observed in $L j g \ln 2-2$. Both $\mathrm{GS}_{2}$ mutant plants are able to grow in a 
similar manner to WT on $0.7 \%$ (vol $/ \mathrm{vol}$ ) $\mathrm{CO}_{2}$ (photorespiration suppressed conditions) but showed an air-sensitive phenotype when the plants were transferred to a normal air atmosphere (photorespiratory active conditions). Typical air-sensitive stress symptoms of photorespiratory mutants were chlorosis and necrosis of the edges of some young leaves, which turned yellow and warped after one to two weeks in air. Mutant plants accumulated significant amounts of ammonium when transferred to air as a result of $\mathrm{GS}_{2}$ deficiency. However, the photorespiratory mutants could be rescued when transferred back to high $\mathrm{CO}_{2}$ (Orea et al. 2002).

Ljgln2-1 and Ljgln2-2 are the first photorespiratory mutants deficient in plastid $\mathrm{GS}_{2}$ isolated in legumes and represent the perfect tool for the study of the possible relationship between $\mathrm{GS}_{2}$, photorespiration, and nodulation, which has not been sufficiently studied to date. This investigation is particularly intriguing, as we report, in this paper, a significant presence of the $\mathrm{GS}_{2}$ isoform in L. japonicus nodule tissues associated with $40 \%$ of the total nodular GS biosynthetic activity. Furthermore, we compared the effect of photorespiration on nodule formation and functioning in WT and $\mathrm{GS}_{2}$ mutants subjected to different $\mathrm{CO}_{2}$ atmospheric conditions, establishing the influence of photorespiratory metabolism and plastidic $\mathrm{GS}_{2}$ on symbiotic performances.

\section{RESULTS}

\section{GS enzyme activity and protein levels}

in WT and Ljgln2 mutant nodules.

In order to determine if the mutant plants were affected in nodule GS enzyme activity, biosynthetic GS activity was examined comparatively in crude nodule extracts of WT and mutant plants (Fig. 1A). The results showed that mutant nodules had around $40 \%$ reduction of total nodule GS activity compared with the WT, thus indicating that $\mathrm{GS}_{2}$ has a very signifi-

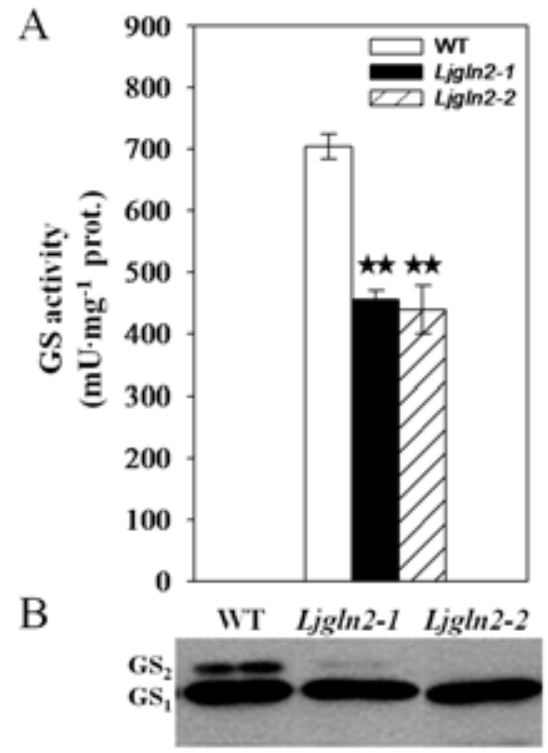

Fig. 1. A, Comparison of biosynthetic glutamine synthetase (GS) activity in crude extracts from nodules of Lotus japonicus wild type (WT) and Ljgln2-1 and Ljgln2-2 mutants. Plants were inoculated with Mesorhizobium loti TONO JA76 and were grown in high $\mathrm{CO}_{2}$ conditions for 6 weeks. Values are the means of two different determinations for each of three independent biological replicates. Error bars represent standard error. ** indicates significant difference between WT and mutant plants as determined by Student's test $(P<0.01)$. B, Immunodetection of plastidic $\left(\mathrm{GS}_{2}\right)$ and cytosolic $\left(\mathrm{GS}_{1}\right)$ polypeptides in crude extracts from $L$. japonicus WT and mutant nodules analyzed by sodium dodecyl sulfate-polyacrylamide gel electrophoresis. Total protein $(10 \mu \mathrm{g})$ were loaded on each case. cant contribution to the total levels of GS activity present in nodules of L. japonicus plants. A Western blot analysis of nodule crude extracts was carried out to determine the presence of $\mathrm{GS}_{1}$ and $\mathrm{GS}_{2}$ polypeptides in the plant nodules. The results revealed the presence of the 45 - and $39-\mathrm{kDa}\left(\mathrm{GS}_{2}\right.$ and $\mathrm{GS}_{1}$, respectively) polypeptides in nodules of WT plants (Fig. 1B). A comparative Western blot analysis of Ljgln2-1 and Ljgln2-2 mutant nodules showed a similar level of the $\mathrm{GS}_{1}$ polypeptide in both genotypes, analogous also to that of the WT, whereas the $\mathrm{GS}_{2}$ polypeptide was undetectable in nodules of Ljgln2-2 mutant and only a faint band could be observed in Ljgln2-1, in contrast to the WT (Fig. 1B). These results indicated that mutants Ljgln2-1 and Ljgln2-2 are not only deficient in the $\mathrm{GS}_{2}$ isoform from leaves and roots as previously reported for nonnodulated plants (Orea et al. 2002) but also in the $\mathrm{GS}_{2}$ isoform from nodules, which must be responsible for at least $40 \%$ of GS activity in this organ.

\section{Nodulation tests}

of Ljgln2-1 and Ljgln2-2 photorespiratory mutants.

The rate of nodulation was compared in $L j g \ln 2-1, L j g \ln 2-2$, and WT plants. Ljgln2-2 mutant plants grown in nonphotorespiratory conditions $\left(0.7 \% \mathrm{CO}_{2}\right)$ showed similar nodulation rates to WT plants (Fig. 2). However, around 30\% fewer nodules were counted for Ljgln2-1 mutant plants after 35 days postinoculation (dpi). Nodule nitrogen-fixation ability was analyzed by acetylene reduction activity (ARA), finding similar levels of this activity per gram of fresh weight (FW) in nodules of both mutant plants compared with the WT (data not shown). Similar results were obtained using different rhizobial strains (NZP2235, R7A) or plant growth systems (agar tubes, Magenta boxes) (data not shown). The fact that mutant plants were able to establish symbiosis and fix nitrogen in a similar way than WT indicated that $\mathrm{GS}_{2}$ isoenzyme was not essential for nodulation and nitrogen-fixation processes under nonphotorespiratory conditions.

Comparison of nodulation properties of WT and $\mathbf{G S}_{2}$ deficient mutants under photorespiratory-active and photorespiratory-suppressed conditions.

Since $\mathrm{GS}_{2}$ protein is involved in photorespiratory ammonium reassimilation (Orea et al. 2002), it was of interest to analyze

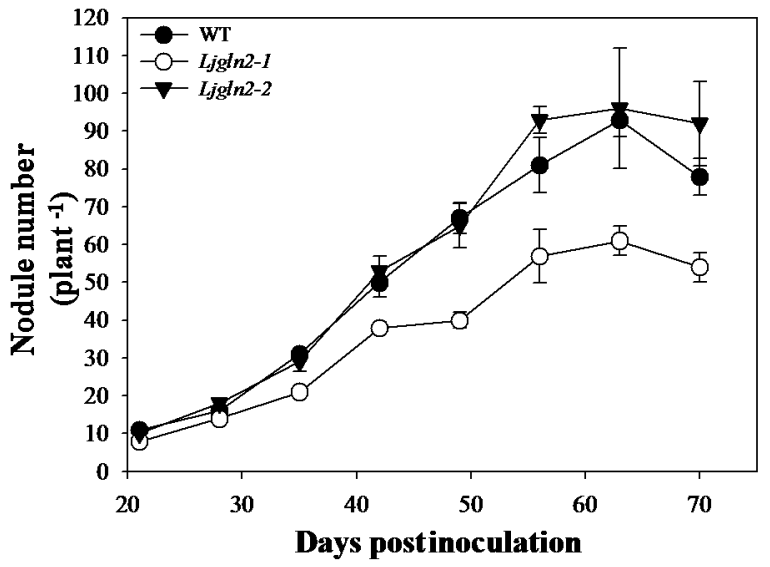

Fig. 2. Nodulation rate of Lotus japonicus wild type (WT) and Ljgln2-1 and Ljgln2-2 mutant plants. Plants were germinated in agar and water plates, were transferred to pots after 4 days, and were inoculated with the Mesorhizobium loti TONO JA76 strain. The plants were grown in high $\mathrm{CO}_{2}$ conditions and nodules were counted for 10 weeks. Values are the means of five different biological replicates and error bars represent standard error. Black circles $=$ WT plants, white circles $=$ Ljgln2-1 plants, and black triangles $=$ Ljgln2-2 plants. 
the effects of $\mathrm{GS}_{2}$ deficiency and photorespiration on the nodulation process and nitrogen fixation. For this purpose, WT and Ljgln2-1 and Ljgln2-2 mutants were transferred from high $\mathrm{CO}_{2}$ (photorespiration suppressed) to normal air (photorespiration active) conditions. Two different times of nodule development were selected, 20 and 40 dpi. In the first case, plants growing for 20 days in high $\mathrm{CO}_{2}$ were compared with plants growing 10 days in high $\mathrm{CO}_{2}$ that were then transferred to air for another 10 days. In the second case, the plants were maintained for 40 days in $\mathrm{CO}_{2}$ and were compared with plants cultivated for 30 days in high $\mathrm{CO}_{2}$ that were then transferred to air for another 10 days. Tables 1 and 2 show that the transfer of WT and mutant plants from high $\mathrm{CO}_{2}$ to air affected, in all cases, the number of nodules obtained, the FW of nodules, as well as the levels of ARA, which were substantially reduced compared with the plants maintained in high $\mathrm{CO}_{2}$. These data indicate that the photorespiratory activity of the plant generates a negative influence in nodule formation, development, and function. At 20 dpi, Ljgln2-1 and Ljgln2-2 mutants were affected in a very similar way to the WT (Table 1 ), thus indicating that the additional lack of $\mathrm{GS}_{2}$ does not seem to further influence nodulation at this plant developmental stage. However, results were quite different at a later stage of plant development (40 dpi) (Table 2), since in this case, mutant nodules were considerably more affected than the WT. The ratio between nodule FW and nodule number as well as the specific ARA per nodule FW ratio were considerably lower for the mutants than for WT plants transferred to air (but not for control plants maintained in high $\mathrm{CO}_{2}$ ), indicating that $\mathrm{GS}_{2}$ deficiency affects nodule mass and function in 40-dpi plants, particularly under photorespiratory active conditions. Furthermore, the number and FW of mutant nodules showed up to a 40 to $60 \%$ decrease, and in addition, ARA was 85 to $90 \%$ inhibited with regard to the mutant plants maintained in high $\mathrm{CO}_{2}$ conditions. These results illustrate the relationship existing between the photorespiratory activity of the plant and nodule development and functioning. Noteworthy, total number, FW, and ARA of nodules were also diminished in Ljgln2-1 mutant plants maintained in high $\mathrm{CO}_{2}$ conditions at 40 dpi (Table 2) but not in mutant plants maintained in high $\mathrm{CO}_{2}$ conditions at 20 dpi (Table 1). This indicates that mutant nodules were also affected at this later stage of growth as a result of $\mathrm{GS}_{2}$ deficiency, independently of photorespiration, in agreement with nodulation rate data shown in Figure 2. All these results revealed that $\mathrm{GS}_{2}$ deficiency caused deleterious effects in nodules of Ljgln2-1 and Ljgln2-2 mutant plants, particularly at the later stages of plant development.

\section{Optical microscopy.}

Optical microscopy analyses were carried out in nodule sections from WT and mutant plants in order to check for any possible morphological changes associated to nodule development, either in plants maintained in high $\mathrm{CO}_{2}$ or after transfer to air conditions. No major differences regarding size and development of nodules were observed in nodule sections from WT and mutant plants in high $\mathrm{CO}_{2}$ at 20 or 40 dpi (Fig. 3). In contrast, the analysis of nodule sections from mutant plants cultivated in high $\mathrm{CO}_{2}$ and transferred to air conditions showed significant alterations. A slight disappearance of starch granules in mutant nodules was observed in nodules of mutant plants cultivated 10 days in $\mathrm{CO}_{2}$ and transferred to air for 10 days more, as compared with WT grown under the same conditions (data not shown). Furthermore, severe differences were obtained in older nodule sections from plants growing 30 days in high $\mathrm{CO}_{2}$ and transferred to an air atmosphere for another 10 days. In this case, reduced size and a complete lack of starch granules (Fig. 4A to F) were two important differences observed in mutant nodules when compared with WT nodules. In addition, a larger vacuolated area was observed in the infected cells of nodule sections from both mutant plants at $40 \mathrm{dpi}$ as compared with WT (Fig. 4D to F) and, in the Ljgln2-2 nodules, regions of infected cells with less densely packed bacteroids, which have previously been reported in L. japonicus fix- mutants, could be clearly recognized (Fig. 4G) (Hossain et al. 2006). These results revealed that mutant plant nodules showed a higher extent of cellular lysis, possibly produced as a result of an anticipated senescence.

Table 1. Nodulation parameters of Lotus japonicus wild type (WT) and Ljgln2-1 and Ljgln2-2 mutants at 20 days postinoculation ${ }^{\text {a }}$

\begin{tabular}{|c|c|c|c|c|c|c|}
\hline \multirow[b]{2}{*}{ Parameter } & \multicolumn{3}{|c|}{ Set 1} & \multicolumn{3}{|c|}{ Set 2} \\
\hline & WT & Ljgln2-1 & Ljgln2-2 & $\mathbf{W T}$ & Ljgln2-1 & Ljgln2-2 \\
\hline Nodule number (plant ${ }^{-1}$ ) & $10.7 \pm 1.3$ & $10.3 \pm 0.7$ & $10.2 \pm 0.9$ & $6.8 \pm 0.2$ & $5.5 \pm 0.6+t$ & $7.4 \pm 1.1$ \\
\hline Nodule FW (mg plant $\left.{ }^{-1}\right)$ & $6.4 \pm 1.1$ & $5.5 \pm 1.0$ & $6.3 \pm 1.3$ & $2.6 \pm 0.4 \ddagger$ & $1.7 \pm 0.0 * \div$ & $2.7 \pm 0.3 \ddagger$ \\
\hline Nodule FW to nodule number ratio & $0.6 \pm 0.0$ & $0.5 \pm 0.1$ & $0.6 \pm 0.1$ & $0.4 \pm 0.1$ & $0.3 \pm 0.0 \ddagger$ & $0.4 \pm 0.0$ \\
\hline ARA $\left(\right.$ plant $\left.^{-1}\right)$ & $101.7 \pm 17.1$ & $135.8 \pm 29.3$ & $135.6 \pm 21.0$ & $15.8 \pm 1.7 \ddagger$ & $11.1 \pm 1.5+\ddagger$ & $21.6 \pm 2.2+\neq$ \\
\hline ARA to odule FW & $15.9 \pm 0.5$ & $24.7 \pm 1.8^{*}$ & $21.5 \pm 1.7 *$ & $6.1 \pm 1.6+t$ & $6.5 \pm 0.8+t$ & $8.0 \pm 1.7++$ \\
\hline
\end{tabular}

${ }^{\text {a }}$ For Set 1, inoculated plants were maintained in high $\mathrm{CO}_{2}$ for 20 days, and for Set 2, plants were cultivated 10 days in high $\mathrm{CO}_{2}$ and were then transferred to air for 10 days more. Acetylene reduction activity (ARA) is expressed as nanomole ethylene per hour per plant. ARA to nodule fresh weight (FW) is expressed as nanomole ethylene per milligram of FW nodules per hour. Values are the means of three determinations for each of three different biological replicates \pm standard error. * indicates significant differences between WT and mutant plants in each condition, + indicates significant differences between $\mathrm{CO}_{2}$ and air conditions for each plant type as determined by Student's test. * $P<0.05 ; * * P<0.01 ; \ddagger P<0.05 ;$; $P<0.01$.

Table 2. Nodulation parameters of Lotus japonicus wild type (WT) and Ljgln2-1 and Ljgln2-2 mutants at 40 days postinoculation ${ }^{\mathrm{a}}$

\begin{tabular}{|c|c|c|c|c|c|c|}
\hline \multirow[b]{2}{*}{ Parameter } & \multicolumn{3}{|c|}{ Set 1} & \multicolumn{3}{|c|}{ Set 2} \\
\hline & WT & Ljgln2-1 & Ljgln2-2 & WT & Ljgln2-1 & $L j g \ln 2-2$ \\
\hline Nodule number $\left(\right.$ plant $\left.^{-1}\right)$ & $47.5 \pm 7.5$ & $33.0 \pm 1.0^{*}$ & $40.0 \pm 3.8$ & $34.0 \pm 3.1$ & $19.7 \pm 4.1^{*}$ & $21.0 \pm 5.1 * \leftarrow$ \\
\hline Nodule FW (mg plant $\left.{ }^{-1}\right)$ & $80.7 \pm 9.7$ & $45.6 \pm 7.4^{*}$ & $68.0 \pm 12.0$ & $49.8 \pm 4.6 \div$ & $17.7 \pm 3.6^{* * \ddagger}$ & $23.1 \pm 4.8^{* * \dagger}$ \\
\hline Nodule FW to nodulenumber ratio & $1.7 \pm 0.1$ & $1.4 \pm 0.2$ & $1.7 \pm 0.2$ & $1.5 \pm 0.1$ & $0.9 \pm 0.2 *$ & $1.1 \pm 0.1 * \div$ \\
\hline $\operatorname{ARA}\left(\right.$ plant $\left.^{-1}\right)$ & $801.5 \pm 182.3$ & $409.3 \pm 42.4^{*}$ & $645.9 \pm 7.4$ & $294.1 \pm 36.7 \ddagger$ & $61.1 \pm 21.0 * *+\neq$ & $65.1 \pm 11.4 * *+\neq$ \\
\hline ARA to nodule FW & $9.9 \pm 1.1$ & $9.0 \pm 0.5$ & $9.5 \pm 0.7$ & $5.9 \pm 0.6 \ddagger$ & $3.4 \pm 0.5^{*}+\ddagger$ & $2.8 \pm 0.1 * *+\ddagger$ \\
\hline
\end{tabular}

${ }^{a}$ For Set 1, inoculated plants were maintained in high $\mathrm{CO}_{2}$ for 40 days, and for Set 2, plants were cultivated 30 days in high $\mathrm{CO}_{2}$ and were then transferred to air for 10 days more. Acetylene reduction activity (ARA) is expressed as nanomole ethylene per hour per plant. ARA to nodule fresh weight (FW) is expressed as nanomole ethylene per milligram of FW nodules per hour. Values are the means of three determinations for each of three different biological replicates \pm standard error. * indicates significant differences between WT and mutant plants in each condition, $¥$ indicates significant differences between $\mathrm{CO}_{2}$ and air conditions for each plant type as determined by Student's test. * $P<0.05 ; * * P<0.01 ; \ddagger P<0.05 ; \neq+P<0.01$. 
These results are also in agreement with the reduction in FW and ARA of nodules of mutant plants observed in these conditions (Table 2), confirming the restrictions on nodule function when the plants were transferred from high $\mathrm{CO}_{2}$ to an air atmosphere.

\section{Measurement of carbohydrate content in nodules.}

In order to confirm the reduction of starch content observed by optical microscopy in nodules of mutant plants transferred to air conditions, starch content assays were carried out in $L$. japonicus nodules from WT and Ljgln2-1 and Ljgln2-2 mutant

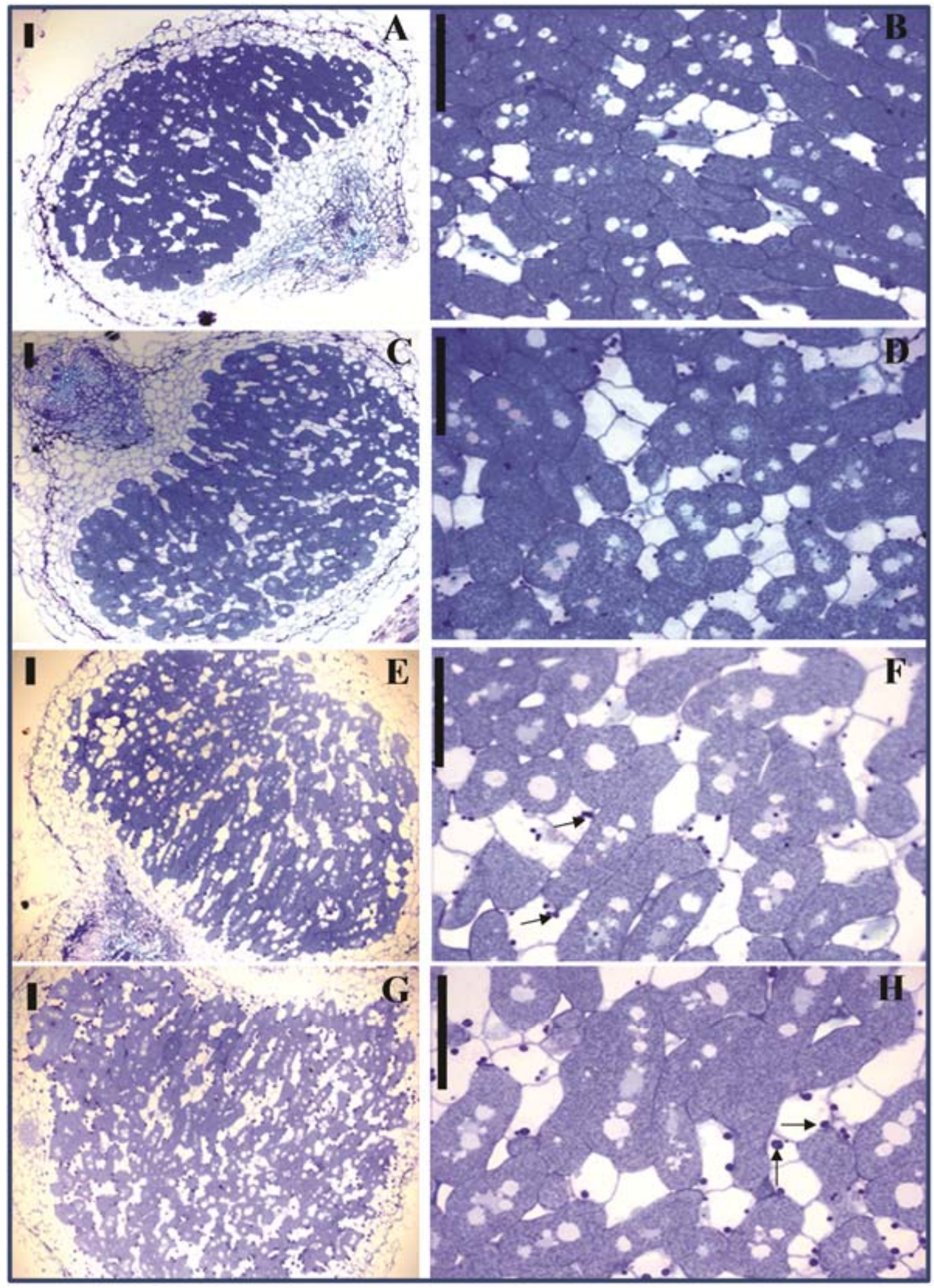

Fig. 3. Optical microscopy of representative nodule sections of Lotus japonicus wild type (WT) and mutant Ljgln2-1 plants. A to D, Plants grown in high $\mathrm{CO}_{2}$ conditions for 20 days. $\mathbf{E}$ to $\mathbf{H}$, Plants grown in high $\mathrm{CO}_{2}$ conditions for 40 days. A, B, E, and F, WT nodules. C, D, G, and H, Ljgln2-1 nodules. Ljgln2-2 data were very similar to $L j g \ln 2-1$ data. The image magnification increases from left to right. Arrows indicate starch granules. Black bars indicate a length of $150 \mu \mathrm{m}$. Sections were stained with $1 \%$ basic toluidine blue. 
plants. The analysis revealed a strong diminution of starch content in nodules of plants transferred to air, this effect being more remarkable in nodules from the mutants, which presented a reduction of about 85 to $90 \%$ of starch content in plants cultivated in high $\mathrm{CO}_{2}$ conditions (Fig. 5). Thus, these data confirmed the reduction of starch granules observed in the nodule sections by optical microscopy. Interestingly, a reduction in starch nodule content that was not revealed by the optical microscopy analysis was observed between WT and mutant plants grown for 40 days in high $\mathrm{CO}_{2}$ conditions (about 50\% less in the Ljgln2-2 background), indicating a photorespiration-independent effect.
We further studied the levels of other carbon compounds, such as glucose, fructose and sucrose, in the plant nodule extracts (Fig. 6). In nodules of WT plants growing in high $\mathrm{CO}_{2}$ conditions, the levels of sucrose were considerably higher than those of glucose and fructose (about 20 and 50 times higher, respectively). Interestingly, under these photorespiration-suppressed conditions, the relative levels of sucrose were considerably lower in nodules from mutant plants with respect to WT, showing around $60 \%$ reduction. When the plants were transferred to air, a major reduction in sucrose was observed in nodules from mutant plants, which showed around 20 to $35 \%$

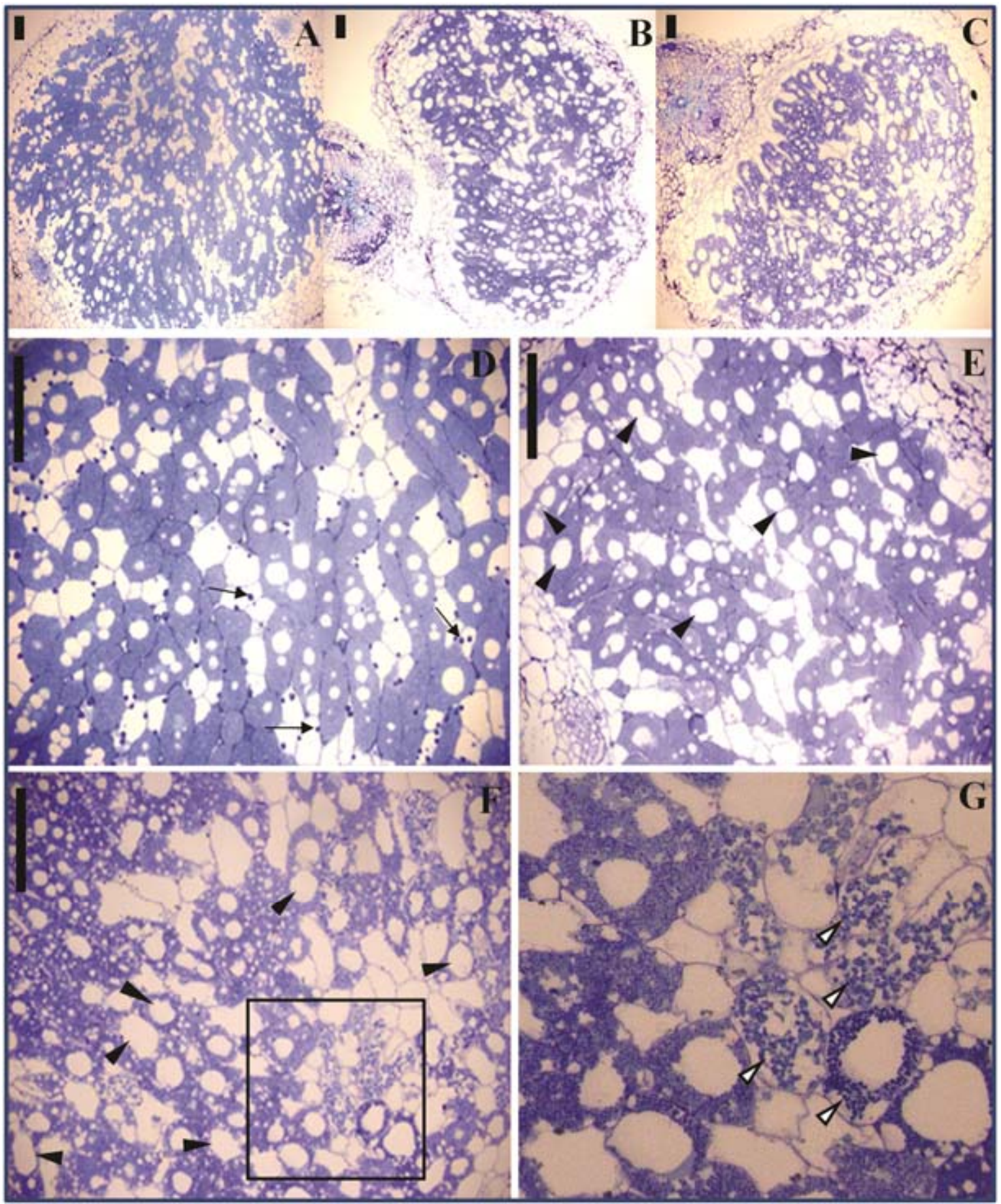

Fig. 4. Optical microscopy of representative nodule sections of Lotus japonicus wild type (WT) and mutant plants grown in high $\mathrm{CO}_{2}$ conditions for 30 days and were transferred to air for 10 days more. A and D, WT nodule. B and E, Ljgln2-1 nodule. $\mathbf{C}$ and $\mathbf{F}, \operatorname{Ljgln} 2-2$ nodule. G, Enlargement of the square in F. Black arrows indicate starch granules. Black arrowheads indicate largely vacuolated infected cells. White arrowheads indicate infected cells that exhibit disintegration with less-dense and aggregated bacteroids. Black bars indicate a length of $150 \mu \mathrm{m}$. Sections were stained with $1 \%$ basic toluidine blue. 
of the sucrose levels obtained in high $\mathrm{CO}_{2}$ conditions. These results revealed the existence of alterations in carbon metabolism of mutant nodules, under both photorespiratory-active and -suppressed conditions.

\section{DISCUSSION}

Photorespiration is a consequence of the oxygenation of ribulose-1,5-bisphosphate and the release of glycolate, catalyzed by Rubisco (Keys 2006). This process has been extensively studied. To date however, how photorespiratory metabolism affects nodulation has not been described. Our work demonstrates that the transfer of high $\mathrm{CO}_{2}$-grown nodulated plants (photorespiration-suppressed condition) to an ordinary air atmosphere (photorespiration-active condition) results in a dramatic reduction in nodule $\mathrm{FW}$ (40 to $60 \%$ decrease) and ARA activity (60 to $85 \%$ decrease) for the WT L. japonicus plants (Tables 1 and 2).

Sucrose was the predominant sugar quantified in nodules of L. japonicus WT and mutant plants (Fig. 6), as also found by other researchers for WT plants (López et al. 2008). This carbohydrate is the first photosynthate supplied to nodules and, consequently, nitrogen fixation in legume nodules is highly dependent on the supply of sucrose delivered from the phloem (Gordon et al. 1999). Carbohydrate analysis revealed a diminution of these compounds in WT nodules of plants grown in high $\mathrm{CO}_{2}$ that were then transferred to air (in particular, starch and sucrose contents). Since the levels of sucrose diminished, the reduction of starch content can also be explained by the sucrose reduction. Starch is the main storage compound when carbon levels are high. In fact, electron micrographs have previously suggested the presence of higher starch content in nodules grown at elevated $\mathrm{CO}_{2}$ (Phillips et al. 1976). When L. japonicus plants are transferred to air, photorespiration begins and $\mathrm{CO}_{2}$ assimilation is consequently diminished, as it is also the available photosynthate content that can be directed to nodules. This situation leads to alterations of carbon metabolism, and therefore, bacteroids are limited in carbon compound levels, causing reduction of atmospheric nitrogen fixation (Tables 1 and 2). So, our data indicate that the photorespiratory activity of the plant influences nitrogen fixation negatively by means of a limitation of carbon flux.

Furthermore, the availability of two different photorespiratory mutants with ordinary levels of $\mathrm{GS}_{1}$ but specifically lack-

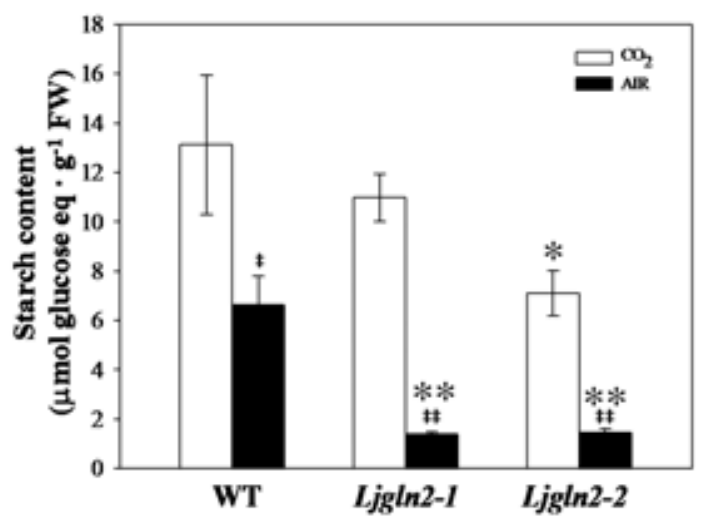

Fig. 5. Starch content of nodules from Lotus japonicus wild type (WT) and mutants cultivated in $\mathrm{CO}_{2}$-enriched atmosphere and transferred to air. Plants at 40 days postinoculation were analyzed. Values are the means of two independent determinations for each of three biological replicates. Error bars represent standard error. * indicates significant differences between WT and mutant plants in each condition, $¥$ indicates significant differences between $\mathrm{CO}_{2}$ and air conditions for each plant type as determined by Student's test. $* P<0.05$; ** $P<0.01 ; \ddagger P<0.05$; $\ddagger$ $+P<0.01$. ing in $\mathrm{GS}_{2}$, Ljgln2-1 and Ljgln2-2, allowed us to show that the lack of $\mathrm{GS}_{2}$ substantially increased the negative effect of photorespiration on the nodulation process and nitrogen fixation in the mutant plants (Table 2). In addition, optical microscopy data revealed alterations in mutant nodules as development restrictions, disappearance of starch granules in the uninfected cells, increase in size of vacuoles, and appearance of regions with lower bacteroid density in the cytoplasm of infected cells, indicative of a cell lysis process (Fig. 4). The data indicate an anticipated senescence in mutant nodules in air atmosphere, concluding that the symbiotic process was highly affected under active photorespiratory conditions. Considering that Ljgln2-1 and Ljgln2-2 mutants are defective in photorespiratory ammonium assimilation, our results emphasize how a "nitrogen" assimilation defect affects "carbon" metabolism and nodule function in L. japonicus. Other recent reports established that antisense inhibition of NADH-GOGAT impairs carbon and nitrogen metabolism in nodules of alfalfa (Cordoba et al. 2003).
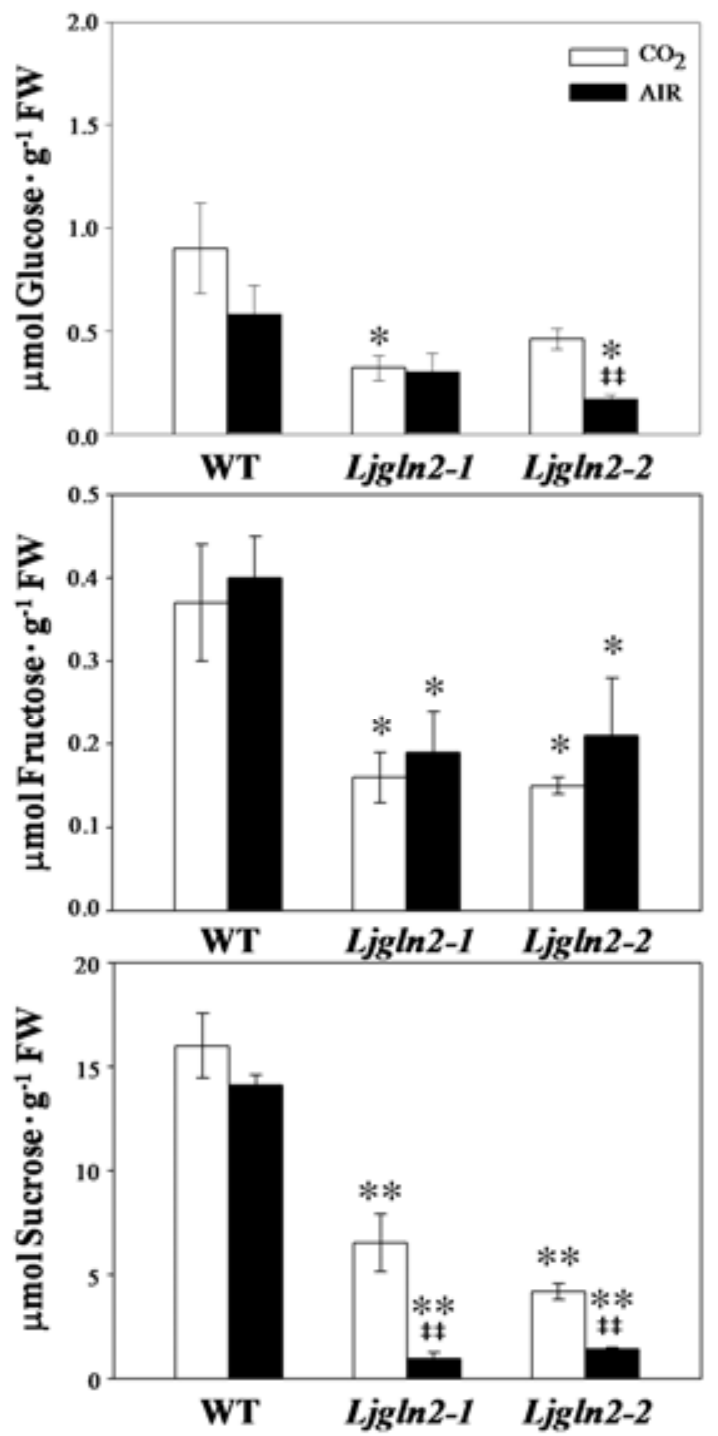

Fig. 6. Glucose, fructose, and sucrose content of nodules from Lotus japonicus wild type (WT) and mutants cultivated in $\mathrm{CO}_{2}$-enriched atmosphere and transferred to air. Plants were analyzed at 40 days postinoculation. Values are the means of four independent determinations. Error bars represent standard error. * indicates significant differences between WT and mutant plants in each condition, $\ddagger$ indicates significant differences between $\mathrm{CO}_{2}$ and air conditions for each plant type as determined by Student's test. $* P<0.05$; ** $P<0.01 ; \ddagger P<0.05$; + $+P<0.01$. 
The requirement of carbon skeletons for ammonium condensation and the supply of reducing equivalents as products of photosynthesis, respiration, and photorespiration pathways is well known (Kinoshita et al. 2011; Masclaux-Daubresse et al. 2010). It was also recently shown that the general nitrogen nutritional status of $L$. japonicus plants can strongly affect the competence for nodule formation (Omrane et al. 2009). Therefore, the reduced number of nodules observed in the Ljgln2-1 and Ljgln2-2 mutants after the shift in air conditions could be explained by the increased amount of nonassimilated ammonium representing an inhibitory signal for the nodule formation pathway (Omrane and Chiurazzi 2009; Omrane et al. 2009).

In the literature it has been reported that nodulated plants growing at atmospheric $\mathrm{CO}_{2}$ enrichment show enhanced whole-plant growth and increased nodule biomass, and the nodules showed higher sugar and starch contents as well as enhancement of some activities related to nodule carbon metabolism and increased ARA (Cabrerizo et al. 2001; Finn and Brun 1982; Ortega et al. 1992). These results indicate that under $\mathrm{CO}_{2}$ enrichment a higher level of carbon must be fixed and directed to nodules. In other studies, plants with $\mathrm{CO}_{2}$ application tended to form fewer and bigger nodules, but in this case, the $\mathrm{CO}_{2}$ was applied around the root and nodule compartment (Fischinger et al. 2010) and not around the shoots, as in our and other studies. However, neither a short- nor a long-term effect on nodule ARA-specific activity has been observed in these plants (Cabrerizo et al. 2001; Vance and Heichel 1991). By contrast, it has recently been described that increases in nodule ARA-specific activity in nodules of plants subjected to high $\mathrm{CO}_{2}$ treatment applied only to the root and nodule compartment (Fischinger et al. 2010). Studies concerning the effect of $\mathrm{CO}_{2}$ enrichment on legume productivity and nodulation are of much interest because of the $\mathrm{CO}_{2}$-mediated greenhouse effect and associated climate change.

It is generally assumed that $\mathrm{GS}_{1}$ is the GS isoenzyme responsible for primary assimilation of the $\mathrm{NH}_{4}{ }^{+}$released by bacteroids (Forde and Cullimore 1989). Different approaches have been utilized to study the physiological impact of altered GS activity in the nodules, using transgenic plants showing a reduction or overexpression in $\mathrm{GS}_{1}$ enzyme activity (Harrison et al. 2003; Ortega et al. 2004). Our results with mutants lacking $\mathrm{GS}_{2}$ confirmed the current view that cytosolic $\mathrm{GS}_{1}$ is sufficient for efficient assimilation of ammonium derived from $\mathrm{N}_{2}$ fixation. A 10 to $30 \%$ reduction of sucrose and glucose nodule content has been reported in L. japonicus plants with reduced nodular $\mathrm{GS}_{1}$ activity (Harrison et al. 2003), but this was correlated to an increase in nodule $\mathrm{FW}$, as a consequence of the induction of an alternative route of ammonium assimilation through asparagine synthetase activity, leading to an increase of Asn content and a more active utilization of $\mathrm{C}$ skeletons exported from the shoot (Carvalho et al. 2003; Harrison et al; 2003).

The presence of plastid $\mathrm{GS}_{2}$ isoform in nodules, as reported for Medicago truncatula (Carvalho et al. 1997; Melo et al. 2003), has also been shown here for L. japonicus. The availability of $\mathrm{GS}_{2}$ mutants from this plant has enabled us to determine that $\mathrm{GS}_{2}$ accounts for up to $40 \%$ of total nodule GS activity (Fig. 1), a relatively unexpected result, since no decrease was observed in the mutant plants with regard to total GS activity from roots (Orea et al. 2002), a closely related organ to nodules. Our analysis of the symbiotic behavior in mutant plants under nonphotorespiratory conditions indicated a number of phenotypes that could be correlated with the lack of $\mathrm{GS}_{2}$ activity. In mutant plants maintained in high $\mathrm{CO}_{2}$ conditions for 40 days after $M$. loti inoculation, we observed a clear-cut deficiency in carbon metabolism, with a strong reduction in the sucrose nodule content as well as a significant decrease in starch, glucose, and fructose levels compared with WT plants (Figs. 5 and 6). Thus a role of $\mathrm{GS}_{2}$ in the $\mathrm{C} / \mathrm{N}$ balance of $L$. japonicus plants, independent of the photorespiratory activity of the plant, can be established. Furthermore, several differences were found between WT and Ljgln2-1 mutant plants maintained in high $\mathrm{CO}_{2}$ (photorespiration-suppressed conditions) at $40 \mathrm{dpi}$ with regard to nodule number, nodule $\mathrm{FW}$, and ARA activity per plant, thus suggesting that the small amount of inactive $\mathrm{GS}_{2}$ protein present in the Ljgln2-1 mutant may have an effect on nodule function, independently of its main role in photorespiration.

In conclusion, since $L j g \ln 2-1$ and $L j g \ln 2-2$ mutants are the first photorespiratory mutants lacking $\mathrm{GS}_{2}$ isolated in legumes, the work described in this paper gives new insights into the influence of photorespiratory metabolism and $\mathrm{GS}_{2}$ on nodule function and demonstrates the utility of these mutant plants for investigation in this area.

\section{MATERIALS AND METHODS}

\section{Plant growth and rhizobial inoculation.}

L. japonicus (Regel) Larsen cv. Gifu were initially obtained by J. Stougaard (University of Aarhus, Denmark) and were then self-propagated at the University of Seville (Spain). Ljgln2-1 and Ljgln2-2 mutants were isolated from photorespiratory mutant screening as described previously (Márquez et al. 2005; Orea et al. 2002). The homozygous recessive mutant progeny from two consecutive backcrosses of the original mutants was used in this work. WT and mutant seeds were scarified and surface-sterilized, were germinated in agar and water in petri dishes, and were transferred to sterilized pots with vermiculite as solid support. Five seedlings were planted in each plot and were grown in SANYO or IBERCEX growth chambers under 16-h-day and 8-h-night cycles $\left(20\right.$ and $18^{\circ} \mathrm{C}$, respectively), with a photosynthetic flux density of $250 \mu \mathrm{mol} \mathrm{m} \mathrm{m}^{-2} \mathrm{~s}^{-1}$ and a constant humidity of $70 \%$. WT and mutant plants were grown in the presence of $0.7 \%$ (vol/vol) $\mathrm{CO}_{2}$ atmosphere (normally referenced as high $\mathrm{CO}_{2}$ ), obtained by automatic injection and continuous monitoring of $\mathrm{CO}_{2}$, using an infrared gas analyzer in conjunction with a series of solenoid valves. One set of plants was maintained in $\mathrm{CO}_{2}$ (photorespirationsuppressed conditions) during the indicated time and a second set was transferred for a fixed length of time to a growth chamber with normal air (photorespiratory-active conditions). Plants were watered with $40 \mathrm{ml}$ of sterile Hornum nutrient solution (Handberg and Stougaard 1992) without a nitrogen source and supplemented with $3 \mathrm{mM} \mathrm{KCl}$.

M. loti TONO JA76 (Kawaguchi et al. 2002) was grown in YM liquid medium (Vincent 1970 ) at $28^{\circ} \mathrm{C}$ to an optical density at $600 \mathrm{~nm}=1$, and was then collected by centrifugation for $30 \mathrm{~min}$ at $2,408 \times g$ and was resuspended in $0.75 \%$ (wt/vol) $\mathrm{NaCl}$. Once sown in the pots, the plants were inoculated by the addition of $2 \mathrm{ml}$ of this bacterial solution. A control with noninoculated plants was carried out to check for the absence of nodules.

\section{Enzyme assays.}

GS enzyme activity levels in different organs of the plants were determined by the biosynthetic reaction assay as described previously (Montanini et al. 2003), using plant extracts as the enzyme source. Leaves, roots, and nodules were harvested $6 \mathrm{~h}$ after the beginning of the light period. Whole healthy leaves, roots, and nodules from WT and mutant plants were pooled, were quickly frozen in liquid nitrogen, were ground in a mortar, and then, were kept at $-80^{\circ} \mathrm{C}$ until used. Extracts were prepared by grinding frozen tissues $(100 \mathrm{mg}$ wet weight), suspending them in $0.5 \mathrm{ml}$ of extraction buffer (100 
mM Tris- $\mathrm{HCl}, \mathrm{pH} 7.8,5$ mM EDTA, $\mathrm{pH}$ 8, 14 mM $\beta$-mercaptoethanol), and then, centrifuging for $15 \mathrm{~min}$ at $20,800 \times g$. The standard reaction mixture (final volume $100 \mu \mathrm{l}$ ) contained $10 \mu \mathrm{mol}$ of Tris- $\mathrm{HCl}\left(\mathrm{pH} 7.50\right.$, at $\left.25^{\circ} \mathrm{C}\right), 100 \mu \mathrm{mol}$ of L-glutamate, $5 \mu \mathrm{mol}$ of $\mathrm{NH}_{4} \mathrm{Cl}, 5 \mu \mathrm{mol}$ of $\mathrm{MgCl}_{2}, 0.75 \mu \mathrm{mol}$ of ATP (from a $100 \mathrm{mM}$ stock solution, $\mathrm{pH}$ 7.5) and the corresponding amount of crude extract. Following incubation at $37^{\circ} \mathrm{C}$ for 15 min, inorganic phosphate released by ATP hydrolysis was determined, using the malachite green method (Lanzeta et al. 1979). One unit of enzyme activity corresponds to the formation of $1 \mu \mathrm{mol} \mathrm{P}_{\mathrm{i}}$ per min.

Nitrogenase enzyme activity was determined by the acetylene reduction (ARA) assays (Buendía-Clavería et al. 1986) using a Hewlett Packard 5890 II Plus gas chromatographer.

\section{Carbohydrate determinations.}

Frozen powdered leaf, root, or nodule materials ( 0.10 to $0.15 \mathrm{~g}$ ) were extracted for $30 \mathrm{~min}$ at $80^{\circ} \mathrm{C}$ in screw-cap tubes as follows: twice with $1 \mathrm{ml}$ of $80 \%$ aqueous ethanol (buffered with $5 \mathrm{mM}$ HEPES-KOH, pH 7.5), once with $1 \mathrm{ml}$ of $50 \%$ aqueous ethanol (buffered as before), and once with $1 \mathrm{ml}$ of distilled water. Extracts from each step were centrifuged $(20,800 \times g, 5$ min), and the four supernatants were collected, combined, and kept at $-20^{\circ} \mathrm{C}$, until carbohydrate determinations were accomplished. Glucose, fructose, and sucrose in the extracts were measured as described by Stitt and associates (1989). Starch determinations were carried out using the insoluble material obtained in the former extraction procedures. The precipitates were incubated with $1 \mathrm{ml}$ of distilled water for $5 \mathrm{~h}$ at $100^{\circ} \mathrm{C}$ and were cooled at room temperature, and $50 \mu \mathrm{l}$ of each sample was added to $950 \mu \mathrm{l}$ of a reaction mixture containing $80 \mathrm{mM}$ sodium acetate, $\mathrm{pH} 4.9,1.4 \mathrm{U}$ amyloglucosidase, and $2 \mathrm{U} \alpha$-amylase, with further incubation for $12 \mathrm{~h}$ at $37^{\circ} \mathrm{C}$. These preparations were centrifuged at $20,800 \times g$ for $5 \mathrm{~min}$, and $100 \mu \mathrm{l}$ from each supernatant were used for glucose determination, as described above. Starch content was expressed as micromole glucose equivalents per gram of $\mathrm{FW}$ of tissue.

\section{Electrophoresis and Western blot.}

Crude extracts containing $10 \mu \mathrm{g}$ of total protein were analyzed by sodium dodecyl sulfate-polyacrylamide gel electrophoresis on $12 \%$ (wt/vol) acrylamide gels (Laemmli 1970) and were transferred onto polyvinylidene difluoride sheets (Immobilon-P; Millipore, MA, U.S.A.), as described by Pajuelo and associates (1993). Western blot was performed using the ECL Western blotting system (Amersham Biosciences, Piscataway, NJ, U.S.A.) according to Betti and associates (2006).

\section{Optical microscopy.}

L. japonicus nodules were harvested and fixed immediately in $4 \%(\mathrm{vol} / \mathrm{vol})$ paraformaldehyde, $3 \%$ ( vol/vol) glutaraldehyde, $4 \%$ (wt/vol) sucrose, and $50 \mathrm{mM}$ sodium phosphate buffer, $\mathrm{pH} 7.4$, applying vacuum for $2 \mathrm{~h}$, and incubating overnight in fixative solution. The nodules were rinsed twice in $50 \mathrm{mM}$ sodium phosphate buffer and were embedded in Historesin (Poly/bed 812; Polysciences, Warrington, PA, U.S.A.). Fixed nodule sections were cut into $2 \mu \mathrm{m}$ in thickness and stained with $1 \%$ (wt/vol) basic toluidine blue for light microscopy enabling the detection of starch grains.

\section{ACKNOWLEDGMENTS}

Authors wish to acknowledge funding by the European Union (INTEGRAL MRTN-CT-2003-505227; Lotassa FP6-517617), the Junta de Andalucía P.O. FEDER 2007-2013 (Project PO7-CVI-3026), P10-CVI-6368 and BIO-163, and the Italian Ministry of Education (Progetti di Rilevanza Nazionale, PRIN 2008, Prot. 2008WKPAWW). We thank the facility of Integrated Microscopy of the Institute of Genetics and Biophysics for the optical microscopy analysis and nodule sections preparation. The authors thank B. G. Forde and P. J. Lea (Lancaster University, U.K.) for a critical reading of this manuscript, as well as P. Lazzeri (Agrasys S.L., Barcelona, Spain) for English corrections. The technical assistance of M. J. Cubas is gratefully acknowledged.

\section{LITERATURE CITED}

Betti, M., Arcondéguy, T., and Márquez, A. J. 2006. Molecular analysis of two mutants from Lotus japonicus deficient in plastidic glutamine synthetase: Functional properties of purified GLN2 enzymes. Planta 224:1068-1079.

Blackwell, R. D., Murray, A. J. S., and Lea, P. J. 1987. Inhibition of photosynthesis in barley with decreased levels of chloroplastic glutamine synthetase activity. J. Exp. Bot. 38:1799-1809.

Buendía-Clavería, A. M., Ruiz-Sainz, J. E., Cubo-Sánchez, T., and PérezSilva, J. 1986. Studies of symbiotic plasmids in Rhizobium trifolii and fast-growing bacteria that nodulate soybeans. J. Appl. Bacteriol. 61:1-9.

Cabrerizo, P. M., González, E. M., Aparicio-Tejo, P. M., and Arrese-Igor, C. 2001. Continuous $\mathrm{CO}_{2}$ enrichment leads to increased nodule biomass, carbon availability to nodules and activity of carbon-metabolising enzymes but does not enhance specific nitrogen fixation in pea. Physiol. Plant. 113:33-40.

Carvalho, H., Sunkel, C., Salema, R., and Cullimore, J. V. 1997. Heteromeric assembly of the cytosolic glutamine synthetase polypeptides of Medicago truncatula: Complementation of a glnA Escherichia coli mutant with a plant domain-swapped enzyme. Plant Mol. Biol. 35:623632.

Carvalho, H. G., Lopes-Cardoso, I. A., Lima, L. M., Melo, P. M., and Cullimore, J. V. 2003. Nodule-specific modulation of glutamine synthetase in transgenic Medicago truncatula leads to inverse alterations in asparagine synthetase expression. Plant Physiol. 133:243-252.

Cordoba, E., Shishkova, S., Vance, C., and Hernández, G. 2003. Antisense inhibition of NADH-glutamate synthase impairs carbon/nitrogen assimilation in nodules of alfalfa. Plant J. 33:1037-1049.

Coruzzi, G., and Last, R. 2000. Amino acids. Pages 358-410 in: Biochemistry and Molecular Biology of Plants. B. Buchanan, W. Gruissem, and R. Jones, eds. American Society of Plant Physiologists, Rockville, MD, U.S.A.

Cren, M., and Hirel, B. 1999. Glutamine synthetase in higher plants: Regulation of gene and protein expression from the organ to the cell. Plant Cell Physiol. 40:1187-1193.

Díaz, P., Betti, M., Sánchez, D. H., Udvardi, M. K., Monza, J., and Márquez, A. J. 2010. Deficiency in plastidic glutamine synthetase alters proline metabolism and transcriptomic response in Lotus japonicus under drought stress. New Phytol. 188:1001-1013.

Edwards, J. W., Walker, E. L., and Coruzzi, G. M. 1990. Cell-specific expression in transgenic plants reveals nonoverlapping roles for chloroplast and cytosolic glutamine synthetase. Proc. Natl. Acad. Sci. U.S.A. 87:3459-3463.

Ferguson, B. J., Indrasumunar, A., Hayashi, S., Lin, M.-H., Lin, Y.-H., Reid, D. E., and Gresshoff, P. M. 2010. Molecular analysis of legume nodule development and autoregulation. J. Integr. Plant Biol. 52:61-76.

Finn, G. A., and Brun, W. A. 1982. Effect of atmospheric $\mathrm{CO}_{2}$ enrichment on growth, non-structural carbohydrate content, and root nodule activity in soybean. Plant Physiol. 69:327-331.

Fischinger, S. A., Hristozkova, M., Mainassara, Z.-A., and Schulze, J. 2010. Elevated $\mathrm{CO}_{2}$ concentration around alfalfa nodules increases $\mathrm{N}_{2}$ fixation. J. Exp. Bot. 61:121-130.

Forde, B. G., and Cullimore, J. V. 1989. The molecular biology of glutamine synthetase in higher plants. Pages 247-296 in: Oxford Surveys of Plant Molecular and Cell Biology, Vol. 6. B. J. Miflin, ed. Oxford University Press, Oxford.

Gordon, A. J., Minchin, F. R., James, C. L., and Komina, O. 1999. Sucrose synthase in legume nodules is essential for nitrogen fixation. Plant Physiol. 120:867-877.

Handberg, K., and Stougaard, J. 1992. Lotus japonicus, an autogamous, diploid legume species for classical and molecular genetics. Plant J. 2:487-496.

Harrison, J., Pou de Crescenzo, M. A., Sené, O., and Hirel, B. 2003. Does lowering glutamine synthetase activity in nodules modify nitrogen metabolism and growth of Lotus japonicus? Plant Physiol. 133:253-262.

Hossain, M. S., Umehara, Y., and Kouchi, H. 2006. A novel fix ${ }^{-}$symbiotic mutant of Lotus japonicus, Ljsym105, shows impaired development and premature deterioration of nodule-infected cells and symbiosomes. Mol. Plant-Microbe Interact. 19:780-788.

Kamachi, K., Yamaya, T., Hayakawa, T., Mae, T., and Ojima, K. 1992. Vascular bundle-specific localization of cytosolic glutamine synthetase in rice leaves. Plant Physiol. 99:1481-1486. 
Kawaguchi, M., Imaizumi-Anraku, H., Koiwa, H., Niwa, S., Ikuta, A., Syono, K., and Akao, S. 2002. Root, root hair and symbiotic mutants of the model legume Lotus japonicus. Mol. Plant-Microbe Interact. 15:1726.

Keys, A. J. 2006. The re-assimilation of ammonia produced by photorespiration and the nitrogen economy of C3 plants. Photosynth. Res. 87:165175

Kichey, T., Le Gouis, J., Sangwan, B., Hirel, B., and Dubois, F. 2005. Changes in the cellular and subcellular localization of glutamine synthetase and glutamate dehydrogenase during flag leaf senescence in wheat (Triticum aestivum L.). Plant Cell Physiol. 46:964-974.

Kinoshita, H., Nagasaki, J., Yoshikawa, N., Yamamoto, A., Takito, S., Kawasaki, M., Sugiyama, T., Miyake, H., Weber, A. P. M., and Taniguchi, M. 2011. The chloroplastic 2-oxoglutarate/malate transporter has dual function as the malate valve and in carbon/nitrogen metabolism. Plant J. 65:15-26.

Kozaki, A., and Takeba, G. 1996. Photorespiration protects C3 plants from photooxidation. Nature 384:557-650.

Laemmli, U. K. 1970. Cleavage of structural protein during the assembly of the head of bacteriophage T4. Nature 251:614-616.

Lancien, M., Gadal, P., and Hodges, M. 2000. Enzyme redundancy and the importance of 2-oxoglutarate in higher plant ammonium assimilation. Plant Physiol. 123:817-824.

Lanzeta, P. A., Álvarez, L. J., Reinach, P. S., and Cia, O. A. 1979. An improved assay for nanomole amounts of inorganic phosphate. Anal. Biochem. 100:95-97.

Lea, P. J., and Ireland, R. J. 1999. Nitrogen metabolism in higher plants. Pages 1-47 in: Plant Amino Acids: Biochemistry and Biotechnology. B. K. Singh, ed. Marcel Dekker, Inc., New York.

Lodwig, E., and Poole, P. 2003. Metabolism of Rhizobium bacteroids. Crit. Rev. Plant Sci. 22:37-78.

Lodwig, E. M., Hosie, A. H. F., Bourdès, A., Findlay, K., Allaway, D., Karunakaran, R., Downie, J. A., and Poole, P. S. 2003. Amino-acid cycling drives nitrogen fixation in the legume-Rhizobium symbiosis. Nature 422:722-726.

López, M., Herrera-Cervera, J. A., Iribarne, C., Tejera, N. A., and Lluch, C. 2008. Growth and nitrogen fixation in Lotus japonicus and Medicago truncatula under $\mathrm{NaCl}$ stress: Nodule carbon metabolism. J. Plant Physiol. 165:641-650.

Márquez, A. J., Betti, M., García-Calderón, M., Palove-Balang, P., Díaz, P., and Monza, J. 2005. Nitrate assimilation in Lotus japonicus. J. Exp.Bot. 56:1741-1749.

Masclaux-Daubresse, C., Daniel-Vedele, F., Dechorgnat, J., Chardon, F., Gaufichon, L., and Suzuki, A. 2010. Nitrogen uptake, assimilation and remobilization in plants: Challenges for sustainable and productive agriculture. Ann. Bot. 105:1141-1157.

Melo, P. M., Lima, L. M., Santos, I. M., Carvalho, H. G., and Cullimore, J V. 2003. Expression of the plastid-located glutamine synthetase of Medicago truncatula. Accumulation of the precursor in root nodules reveals an in vivo control at the level of protein import into plastids. Plant Physiol. 132:390-399.

Montanini, B., Betti, M., Márquez, A. J., Balestrini, R., Bonfante, P., and Ottonello, S. 2003. Distinctive properties and expression profiles of glutamine synthetase from a plant symbiotic fungus. Biochem. J. 373:357-368

Omrane, S., and Chiurazzi, M. 2009. A variety of regulatory mechanisms are involved in the nitrogen-dependent modulation of the nodule organogenesis program in legume roots. Plant Signal. Behav. 4:1066-1068.

Omrane, S., Ferrarini, A., D’Apuzzo, E., Rogato, A., Delledonne, M., and Chiurazzi, M. 2009. Symbiotic competence in Lotus japonicus is affected by plant nitrogen status: Transcriptomic identification of genes affected by a new signalling pathway. New Phytol. 183:380-394.

Orea, A., Pajuelo, P., Pajuelo, E., Quidiello, C., Romero, J. M., and Márquez, A. J. 2002. Isolation of photorespiratory mutants from Lotus japonicus deficient in glutamine synthetase. Physiol. Plant. 115:352-361.

Ortega, J. L., Sánchez, F., Soberón, M., and Lara-Flores, M. 1992. Regulation of nodule glutamine synthetase by $\mathrm{CO}_{2}$ levels in bean (Phaseolus vulgaris L.). Plant Physiol. 98:584-587.

Ortega, J. L., Temple, S. J., Bagga, S., Ghoshroy, S., and SenguptaGopalan, C. 2004. Biochemical and molecular characterization of transgenic Lotus japonicus plants constitutively over-expressing a cytosolic glutamine synthetase gene. Planta 219:807-818.

Pajuelo, E., and Stougaard, J. 2005. Lotus japonicus as a model system. Pages 3-24 in: Lotus japonicus Handbook, A. J. Márquez, ed. Springer, Dordrecht, The Netherlands.

Pajuelo, E., Borrero, J. A., and Márquez, A. J. 1993. Immunological approach to subunit composition of ferredoxin-nitrite reductase from Chlamydomonas reinhardtii. Plant Sci. 95:9-21.

Phillips, D. A., Newell, K. D., Hassell, S. A., and Felling, C. E. 1976. The effect of $\mathrm{CO}_{2}$ enrichment on root nodule development and symbiotic $\mathrm{N}_{2}$ reduction in Pisum sativum L. Amer. J. Bot. 63:356-362.

Sandal, N., Petersen, T. R., Murray, J., Umehara, Y., Karas, B., Yano, K., Kumagai, H., Yoshikawa, M., Saito, K., Hayashi, M., Murakami, Y., Wang, X., Hakoyama, T., Imaizumi-Anraku, H., Sato, S., Kato, T. Chen, W., Hossain, M. S., Shibata, S., Wang, T. L., Yokota, K., Larsen, K., Kanamori, N., Madsen, E., Radutoiu, S., Madsen, L. H., Radu, T. G., Krusell, L., Ooki, Y., Banba, M., Betti, M., Rispail, N., Skot, L., Tuck, E., Perry, J., Yoshida, S., Vickers, K., Pike, J., Mulder, L., Charpentier, M., Müller, J., Ohtomo, R., Kojima, T., Ando, S., Márquez, A. J., Gresshoff, P. M., Harada, K., Webb, J., Hata, S., Suganuma, N., Kouchi, H., Kawasaki, S., Tabata, S., Hayashi, M., Parniske, M. Szczyglowski, K., Kawaguchi, M., and Stougaard, J. 2006. Genetics of symbiosis in L. japonicus: Recombinant inbred lines, comparative genetic maps and map position on 35 symbiotic loci. Mol. Plant-Microbe Interact. 19:80-91.

Seabra, A. R., Vieira, C. P., Cullimore, J. V., and Carvalho, H. G. 2010. Medicago truncatula contains a second gene encoding a plastid located glutamine synthetase exclusively expressed in developing seeds. BMC Plant Biol. 10:183.

Stitt, M., Lilley, R. M., Gerhardt, R., and Heldt, H. W. 1989. Metabolite levels in specific cells and subcellular compartments of plant leaves. Methods Enzymol. 174:518-552.

Teixeira, J., Pereira, S., Cánovas, F., and Salema, R. 2005. Glutamine synthetase of potato (Solanum tuberosum L. cv. Desiree) plants: Cell- and organ-specific expression and differential developmental regulation reveal specific roles in nitrogen assimilation and mobilization. J. Exp. Bot. 56:663-671.

Vance, C. P., and Heichel, G. H. 1991. Carbon in $\mathrm{N}_{2}$ fixation: Limitation or exquisite adaptation. Annu. Rev. Plant Physiol. Plant Mol. Biol. 42:373-392.

Vincent, J. M. 1970. The cultivation, isolation and maintenance of rhizobia. Pages 1-13 in: A Manual for the Practical Study of the RootNodule Bacteria. J. M. Vincent, ed. Blackwell Scientific Publications. Oxford.

Wallsgrove, R. M., Turner, J. C., Hall, N. P., Kendall, A. C., and Bright, S. W. 1987. Barley mutants lacking chloroplast glutamine synthetase-biochemical and genetic analysis. Plant Physiol. 83:155-158.

White, J., Prell, J., James, E. K., and Poole, P. 2007. Nutrient sharing between symbionts. Plant Physiol. 144:604-614.

Woodall, J., and Forde, B. G. 1996. Glutamine synthetase polypeptides in the roots of 55 legume species in relation to their climatic origin and the partitioning of nitrate assimilation. Plant Cell Environ. 19:848-858. 